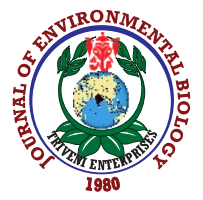

\title{
Patterns of colour inheritance from crossbreeding between Red hybrid tilapia (Oreochromis sp.) and GIFT tilapia (Oreochromis niloticus)
}

\author{
O.F. Nwachi ${ }^{1,3}$, Y.B. Esa ${ }^{1,2 *}$, A. Christianus ${ }^{1}$, A.A. Rahim ${ }^{1}$ and M.S. Kamarudin ${ }^{1}$ \\ ${ }^{1}$ Department of Aquaculture, Faculty of Agriculture, Universiti Putra Malaysia, Serdang, 43400, Malaysia \\ ${ }^{2}$ International Institute of Aquaculture and Aquatic Sciences (I-AQUAS), Universiti Putra Malaysia, Negeri Sembilan, 71050, Malaysia \\ ${ }^{3}$ Department of Fisheries, Delta State University Abraka, Asaba Campus, P.M.B. 1, Nigeria \\ *Corresponding Author Email : yuzine@upm.edu.my
}

\begin{abstract}
Aim: To examine the pattern of colour inheritances from crossbreeding between Red hybrid tilapia (Oreochromis sp.) and GIFT tilapia (Oreochromis niloticus).

Methodology: A total number of 60 broodstock of 30 each of GIFT and Red hybrid tilapia were selected to produce the first filial generation $\left(F_{1}\right)$ and its reciprocal $\mathrm{nF}_{1}$. Pairing of female to male were done in the ratio of 3:1. The same breeding scheme were used to produce the second filial generation $\left(\mathrm{F}_{2}\right)$ and its reciprocal $\mathrm{nBcF}_{1}$

Results: Crossbreeding between Red hybrid tilapia male and GIFT female $\left(F_{1}\right)$ produced phenotypic colours ranging from red (64.61\%), wild type $(11.54 \%)$, red with blotches $(4.96 \%)$ and mixed red-wild type $(18.87 \%)$. The reciprocal cross between GIFT male and Red hybrid tilapia female $(\mathrm{nF} 1)$ produced phenotypic colours ranging from red $(19.65 \%)$, wild type $(64.62 \%)$, red with dark blotches $(4.03 \%)$ and mixed red-wild type $(11.46 \%)$. The second filial $\left(F_{2}\right)$ generation produced phenotypes comprising of $61.17 \%$ wild type, $14.37 \%$ red with dark blotches, $20.04 \%$ mix red-wild type and $4.40 \%$ red type. The backcross $\left(\mathrm{BcF}_{1}\right)$ produced $10.57 \%$, faded wild type $22.76 \%$, red with dark blotches, $28.41 \%$, red with dark posterior and $60.46 \%$ red phenotype while the reciprocal $\left(\mathrm{nBCF}_{1}\right)$ produced $52.89 \%$ faded wild type, $15.11 \%$ red with dark blotches, $6.83 \%$ mix red-wild type and $25.15 \%$ red phenotype.

Interpretation: Manifestation of intermediate and mixed colour phenotypes in $F_{2}$ hybrids and deviation from a simple dominant inheritance might indicate an incomplete dominant inheritance, colour determination in tilapia in this study might be located or linked with the male Y-chromosome due to the fact that more reddish coloured fish were produced when Red hybrid tilapia was selected as the parent.

Key words: Colour phenotype, Crossbreeding, Red hybrid tilapia, GIFT, Mendelian inheritance

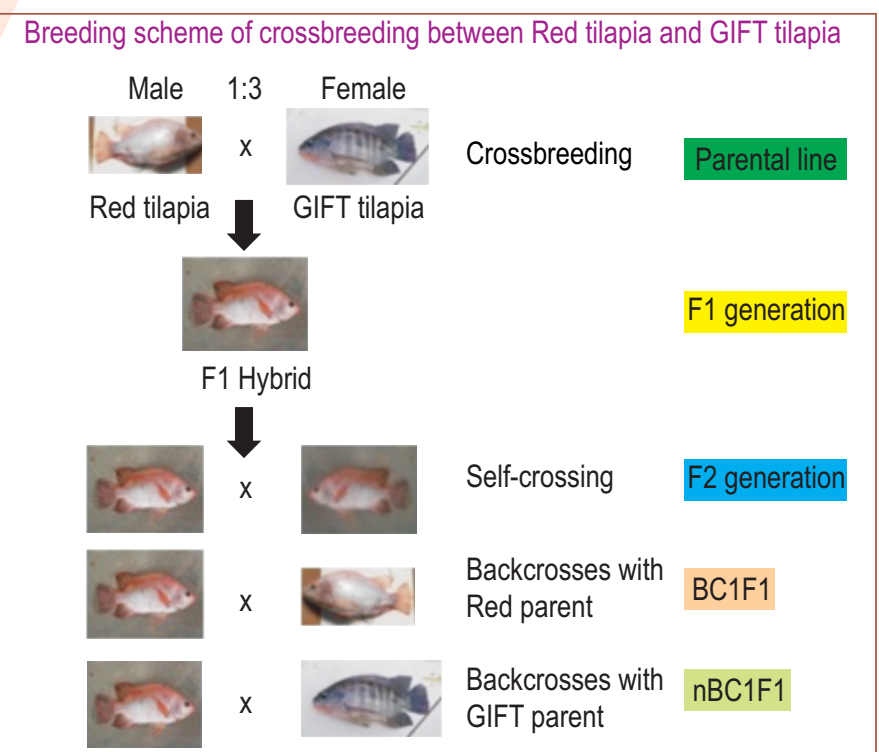

How to cite : Nwachi, O.F., Y.B. Esa, A. Christianus, A.A. Rahim and M.S. Kamarudin: Patterns of colour inheritance from crossbreeding between Red hybrid tilapia (Oreochromis sp.) and GIFT tilapia (Oreochromis niloticus). J. Environ. Biol., 41, 1289-1294 (2020). 


\section{Introduction}

Tilapia is regarded as a fish with great potential for aquaculture because of its ability to reproduce in captivity, accept supplementary feed and can be easily crossbred or hybridized (Benhaïm et al., 2017). The production of GIFT (Genetically Improved Farm Tilapia) strain is an example of highly successful selective breeding programme utilizing genetic variability and heritability information of population level broodstocks of a single species (Oreochromis niloticus) (Hamzah et al., 2014). On the other hand, crossbreeding or hybridization among different tilapia species, either naturally or through artificial propagation has resulted in the production of various strains of Red hybrid tilapia (Watanabe et al., 2002; Rajaee et al., 2010).

Although the initial genetic records on the production of Red hybrid tilapia is not well documented, their derivation is generally attributed to crossbreeding between a mutant reddish orange 0 . mossambicus with other species including normal 0 . aureus, O. niloticus, and O. hornorum (Watanabe et al., 2002). The aims are generally to obtain other desirable traits such as faster growth rate or higher tolerance towards cold temperature or salinity (Rajaee et al., 2010). Nowadays, Red hybrid tilapia strain is one of the most popular tilapia cultures in most countries in Southeast Asia and make up to $85 \%$ of total tilapia production in Malaysia (Ng and Hanim, 2007).

GIFT strain has an estimated cumulative increase of $85 \%$ in growth rate as compared to the base population and exhibits superior traits; fast growth rate, quality fillets and higher survival rate (Beardmore et al., 2001). Nowadays, GIFT strain is distributed worldwide, and is gaining popularity in less developed and developing countries (Trevas, 1982). Nevertheless, the only drawback of GIFT strain is its wild type coloration (greyish black) which is considered less favorable as compared to the red hybrid strain by customers in certain parts of the world (Southeast Asia and South America). Accordingly, the Red hybrid tilapia is preferred over the wild type or black colored tilapia due to its attractive and clean-like red coloration, its near resemblances to reef or marine fishes and its ability to fetch a premium price of USD4.20 per kg in fresh fish market.

Studies on the pattern of inheritance of colour and pigmentation in tilapia has been documented by (Thodesen et al., 2013; Pongthana et al., 2010 and Rajaee et al., 2010), however, the molecular mechanism responsible for the determination of colour and pigmentation is still poorly understood. Accordingly, most of the red genotype of Red hybrid tilapia strains are predicted to be controlled by a single dominant trait (either homozygous dominant RR or heterozygous $\mathrm{Rr}$ ), while the recessive wild type is homozygous recessive (rr) (Wohlfarth et al., 1990; Huang et al.,1988). This includes the Thai strain, Philippine red and Sterling strain. Meanwhile, the Taiwanese and Fijiian strains both exhibit pink body colouration for the homozygous dominant RR allele (Rajaee et al., 2010). In addition, the red colour is often associated with spots or blotches (mainly black but also red) which makes the fish less attractive and affects their market prices. In 0 . niloticus, these blotches are hypothesized to be mainly associated with the heterozygous red fish which carry the $\mathrm{Rr}$ genotype, however, the genetics underlying this trait is still not fully understood (Rajee et al., 2010; McAndrew et al., 1988).

Therefore, this laboratory scale partial diallel crossbreeding experiment was conducted between the GIFT strain (O. niloticus) and a Red hybrid tilapia strain (Oreochromis sp.) that had been cultured and maintained at Universiti Putra Malaysia hatchery for more than 15 years with the objective to determine the genetic pattern of colour inheritance of reciprocal crosses over two generations and to examine the influence of sire gender selection on the phenotype of the offspring.

\section{Materials and Methods}

Broodstock selection : A total number of 60 tilapia fish broodstocks consisting of 30 of each GIFT and Red hybrid tilapia, making up to 48 females and 12 males each, were selected as sires to produce the first filial generation $\left(F_{1}\right)$ and its reciprocal $n F_{1}$. The GIFT strain brood stock was obtained from World Fish Centre (Penang) and maintained in the hatchery for about three generations. Meanwhile, the Red hybrid tilapia strain was originally obtained from two private hatcheries and was also maintained and cultured in the hatchery for more than 10 years. The hatchery record stated that the Red hybrid tilapia strain was a product of hybridization between 0 . niloticus and 0 . mossambicus.

The production of first filial generation $\left(F_{1}\right)$ was done by reciprocal mating between GIFT and Red hybrid tilapia sires. Selected $F_{1}$ dams harbouring only the red body colouration were subsequently selected for the next generation breeding experiments. Accordingly, the $F_{1}$ was self-crossed (female $F_{1}$ with male $\left.F_{1}\right)$ to produce the second filial generation $\left(F_{2}\right)$, the backcross $\left(\mathrm{BcF}_{1}\right)$ was produced by crossing Red hybrid tilapia female with $\mathrm{F}_{1}$ male while the $\mathrm{nBcF}_{1}$ was produced by crossing GIFT female with $\dot{F}_{1}$ male. All fish collections and breeding experiment were conducted and maintained at the UPM Aquaculture Research Station in Puchong, Selangor, Malaysia.

Experimental design : A fish tank of one tonne capacity was used for spawning. The female to male ratio for the breeding experiment was 3:1. A total of 3 selected females of each tilapia strain were stock-up in triplicates per experimental unit, commercial feed was given for a period of 14 days to allow acclimatisation and the greening of water. The male mouths were clipped to reduce the adverse effects of male aggression by the copulating pair. Each experimental units was modelled in triplicate. The males were introduced into the units housed with females after they might have assumed territories and their 
stomach filled with matured eggs that spilled out on gentile massage of the stomach.

The water was allowed to go green to reduce any distraction in the tank from external environment sources. Three pieces of 4 inches $(10.16 \mathrm{~cm})$ diameter and $1 \mathrm{~m}$ length of PVC pipe were placed into the tank to serve as a hiding place for the copulating fish. The fries were assumed to hatch out at the time they were observed at the sides of the tank because of the green water that provide privacy during courtship and fertilization. After hatching, the parent stocks were immediately removed from the hatching tank, the male fish were placed in a solitary tank for two weeks before re-stocking. While swim up fries were reared in the experimental brooding tanks with a partial change of water.

\section{Results and Discussion}

Hybridization has been widely applied as a technique to improve the traits or phenotypes of tilapia in order to make them more desirable in the market (Bentsen et al., 2017; Nwachi and Esa 2016; Neira et al., 2015). Thus, the current crossbreeding study between GIFT and Red hybrid tilapia and its reciprocals, the backcrossing of respective parents to their $F_{1}$ and production of $F_{2}$ by self-crossing of $F_{1}$ were conducted with the aim to produce a putative hybrid GIFT tilapia harbouring the red colouration genotype from the Red hybrid tilapia.
Although, the genetic assessment of red body color in tilapia is not fully understood, the red colouration in 0 . niloticus and most red hybrid tilapia are believed to be controlled by a dominant-inheritance (Lago et al., 2017; Reich et al., 1990; Ferreira 1989). Accordingly, the red body colour in O. niloticus is controlled by a single dominant allele where both homozygous RR or heterozygous Rr produce red body colour while the normal wild type (dark) are controlled by a recessive allele (rr) (Reich et al., 1990). Therefore, in theory, hybridization between a Red hybrid tilapia carrying a dominant red allele (RR) with a GIFT (rr) is expected to produce all $F_{1}$ red colour phenotypes while hybridization between a heterozygous Red hybrid tilapia (Rr) with GIFT (rr) is expected to produce 1 red :1 wild type colour ratio phenotypes. A phenotypic ratio of 3 red: 1 wild type is expected from the offspring of $F_{2}$ generation, while the back cross $\left(\mathrm{BcF}_{1}\right)$ of $F_{1}$ generation with the red parent is expected to produce a 3 red: 1 wild-type ratio while the backcross of $F_{1}$ generation with the GIFT parent is supposed to produce 1 red: 1 wild-type phenotypic ratio.

The results of the crossbreeding study over two generations $\left(F_{1}, F_{2}\right.$ and backcrosses) produced progenies consisting of red and wild type body colour phenotypes. Furthermore, the red colour can be further subcategorized into two body colour patterns; red and red with dark blotches, while the wild type colour can be subcategorized into two body colour

Table 1 : Percentage and average of colour phenotypes of first filial $\left(F_{1}\right)$ generation and its reciprocal crosses between Red hybrid tilapia and GIFT tilapia

\begin{tabular}{|c|c|c|c|c|c|c|c|c|c|c|}
\hline \multicolumn{2}{|c|}{ Mating } & \multirow[b]{3}{*}{ Rep. } & \multicolumn{3}{|c|}{ Genotype of parents } & \multicolumn{2}{|r|}{ Colour } & & & \multirow{3}{*}{$\begin{array}{l}\text { Ratio } \\
\text { Red: Wild-type }\end{array}$} \\
\hline \multirow[b]{2}{*}{ ○ } & \multirow[b]{2}{*}{$0^{n}$} & & \multirow[b]{2}{*}{$\mathrm{N}$} & \multirow[b]{2}{*}{ ○ } & \multirow[b]{2}{*}{$0^{n}$} & & Red & \multicolumn{2}{|c|}{ Wild-type } & \\
\hline & & & & & & Red & $\begin{array}{l}\text { Red with dark } \\
\text { blotches }\end{array}$ & $\begin{array}{l}\text { Mixed red- } \\
\text { wild type }\end{array}$ & Wild-type & \\
\hline \multirow[t]{4}{*}{ GIFT } & Red & 1 & 292 & $\mathrm{rr}$ & $\mathrm{Rr}$ & 136 & 14 & 86 & 56 & $1: 1$ \\
\hline & & 2 & 232 & $\mathrm{rr}$ & $\mathrm{Rr}$ & 107 & 12 & 67 & 48 & $1: 1$ \\
\hline & & 3 & 323 & $\mathrm{rr}$ & $\mathrm{Rr}$ & 150 & 16 & 87 & 70 & $1: 1$ \\
\hline & & & & & Total & \multicolumn{2}{|c|}{435} & \multicolumn{2}{|l|}{414} & $1: 1$ \\
\hline \multirow[t]{4}{*}{ Red } & GIFT & 1 & 281 & $\operatorname{Rr}$ & $\mathrm{rr}$ & 84 & 44 & 30 & 123 & $1: 1$ \\
\hline & & 2 & 306 & $\mathrm{Rr}$ & $\mathrm{rr}$ & 90 & 53 & 35 & 128 & $1: 1$ \\
\hline & & 3 & 329 & $\mathrm{Rr}$ & $\mathrm{rr}$ & 99 & 52 & 42 & 136 & $1: 1$ \\
\hline & & & & & Total & \multicolumn{2}{|c|}{422} & \multicolumn{2}{|c|}{494} & $1: 1$ \\
\hline \multirow[t]{4}{*}{ Red } & Red & 1 & 321 & $\operatorname{Rr}$ & $\mathrm{Rr}$ & 200 & 45 & 0 & 76 & $3: 1$ \\
\hline & & 2 & 320 & $\mathrm{Rr}$ & $\mathrm{Rr}$ & 198 & 44 & 0 & 78 & $3: 1$ \\
\hline & & 3 & 341 & $\mathrm{Rr}$ & $\mathrm{Rr}$ & 206 & 52 & 0 & 83 & $3: 1$ \\
\hline & & & & & Total & \multicolumn{2}{|c|}{745} & \multicolumn{2}{|c|}{237} & $3: 1$ \\
\hline \multirow[t]{4}{*}{ GIFT } & GIFT & 1 & 311 & $\mathrm{rr}$ & $\mathrm{rr}$ & 0 & 0 & 0 & 311 & $0: 1$ \\
\hline & & 2 & 324 & $\mathrm{rr}$ & $\mathrm{rr}$ & 0 & 0 & 0 & 324 & $0: 1$ \\
\hline & & 3 & 343 & $\mathrm{rr}$ & $\mathrm{rr}$ & 0 & 0 & 0 & 343 & $0: 1$ \\
\hline & & & & & Total & & & \multicolumn{2}{|c|}{978} & $0: 1$ \\
\hline
\end{tabular}

Rep $=$ Number of replicates, $\mathrm{N}=$ Offspring number 
patterns; the typical wild type (grey black) and a diluted black with slightly red blotches (identified as mixed red-wild type) as shown in Table 1 and Fig. 1 (a-d). In fact, the 1 red: 1 wild type ratio found in the $F_{1}$ generation indicated that the red hybrid parent selected for the study may carry the heterozygous $\mathrm{Rr}$ genotype. On the other hand, the red with dark blotches pattern can be categorized as exhibiting the dominant $\mathrm{Rr}$ phenotype as well, since blotching is presumed to be genetically associated with the "r" gene in the red tilapia strain (Rajaee et al., 2010). Meanwhile, the mixed redwild type colour pattern presumably carried the same recessive rr genotype with the wild type colour. The control crosses of the Red hybrid female $X$ Red hybrid male produced a 3 red: 1 wild type ratio, while the control GIFT female X GIFT male produced a 0 red: 1 wild type ratio, in accordance with the Mendelian inheritance pattern.

The crossing of first filial generation $\left(F_{1}\right)$ which produced the $\mathrm{F}_{2}$, backross $\mathrm{BcF}_{1}$ and reciprocal $\mathrm{nBcF}_{1}$ also produced four colour phenotypes similar to the F1 hybrid generation. However, the percentages of the observed phenotypes differed depending

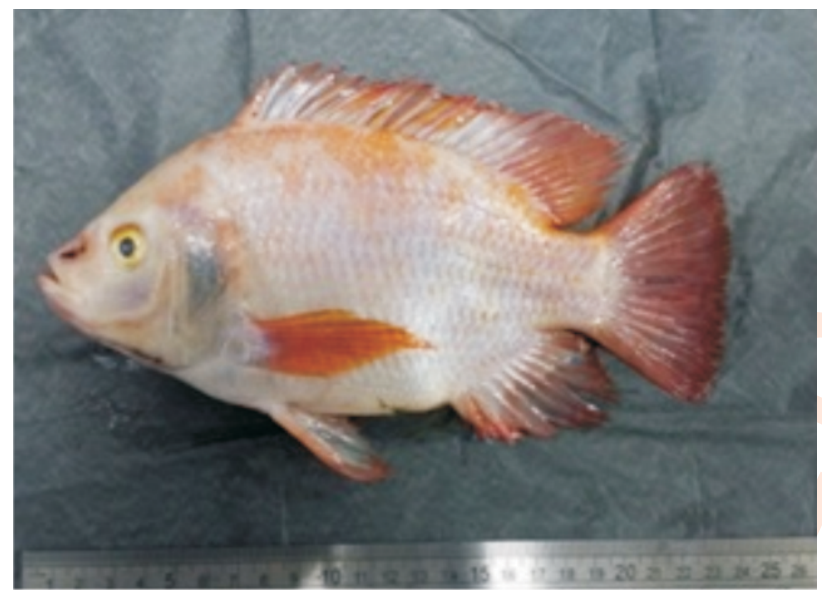

(a) Red

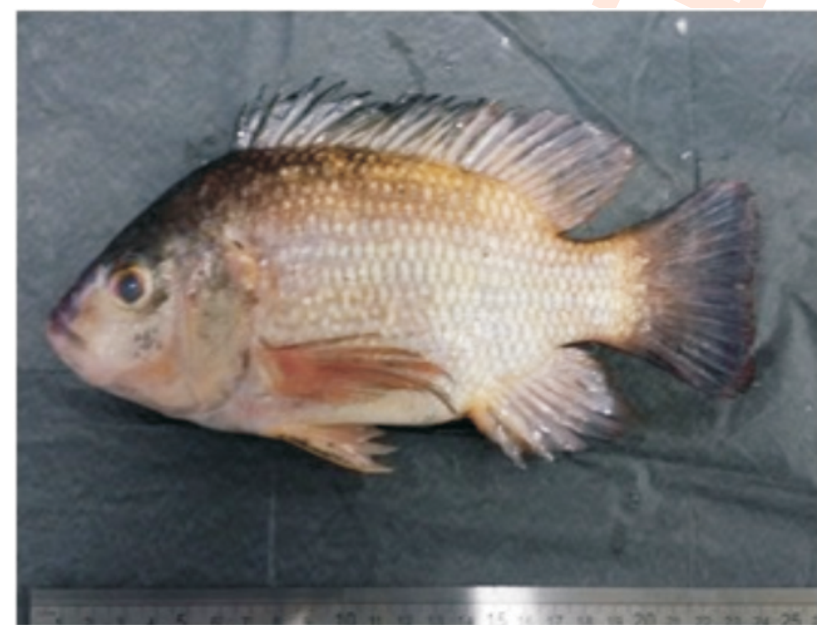

(c) Mix red-wild type on the paired crosses. The self cross between first filial generation $\left(F_{1} \times F_{1}\right)$ produced the second filial generation $\left(F_{2}\right)$ offspring with $43.91 \%$ red type, $28.67 \%$ red with blotches, $5.04 \%$ mix red-wild type and $22.38 \%$ wild type colour (Table 2 ).

On the other hand, the backcross mating $\left(\mathrm{BcF}_{1}\right)$ between Red hybrid tilapia and $F_{1}$ hybrid produced backcross generation comprising of $44.13 \%$ red type, $30.87 \%$ red with dark blotches, $5.87 \%$ mix red-wild type and $19.23 \%$ red colour phenotype. Meanwhile, the reciprocal crossing between GIFT with the $F_{1}$ hybrid produced $34,42 \%$ red type, $15.52 \%$ red with dark blotches, 12.25 $\%$ mix red-wild type and $37.79 \%$ wild type phenotype (Table 2 ).

Nevertheless, the intermediate (mixed red-wild type) colour pattern observed in the $F_{1}$ hybrids, $F 2$ hybrids and backcrosses raised question on whether the pattern of inheritance truly follow the simple Mendelian dominant-recessive pattern commonly found in Red hybrid tilapia as suggested by previous studies (Wohlfarth et al., 1990; Reich et al., 1990; Rajaee et al., 2010; Lago et al., 2017).

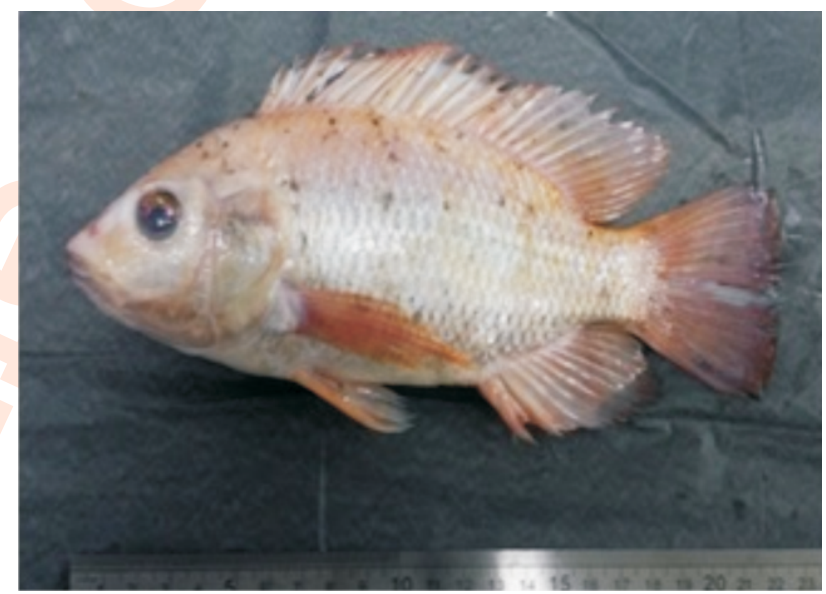

(b) Red with dark blotches

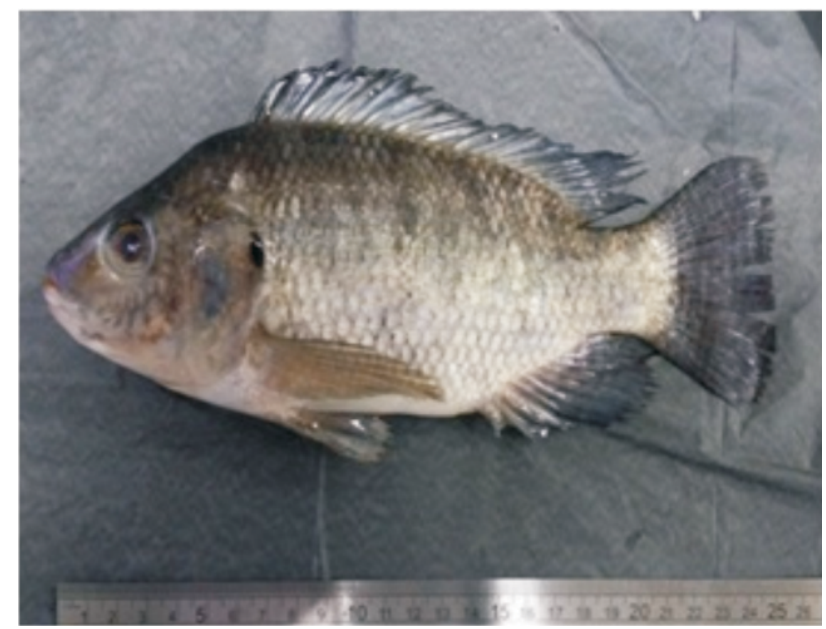

(d) Wild type

Fig. 1 (a-d) : The four colour patterns from reciprocal crossbreeding between Red hybrid tilapia and GIFT tilapia. 
Table 2 : Percentage and average of colour phenotypes of second filial $\left(F_{2}\right)$, backcross $\left(B c F_{1}\right)$ and its reciprocal $\left(n B c F_{1}\right)$

\begin{tabular}{|c|c|c|c|c|c|c|c|c|c|c|}
\hline \multicolumn{2}{|c|}{ Mating } & \multicolumn{4}{|c|}{ Genotype of parents } & \multicolumn{3}{|c|}{ Colour } & & \multirow{3}{*}{$\begin{array}{l}\text { Ratio } \\
\text { Red:Wild-type }\end{array}$} \\
\hline \multirow[b]{2}{*}{ Q } & \multirow[b]{2}{*}{$0^{n}$} & \multirow[b]{2}{*}{ Rep. } & \multirow[b]{2}{*}{$\mathbf{N}$} & \multirow[b]{2}{*}{ q } & \multirow[b]{2}{*}{$0^{n}$} & \multirow[b]{2}{*}{ Red } & Red & \multicolumn{2}{|c|}{ Wild-type } & \\
\hline & & & & & & & $\begin{array}{l}\text { Red with dark } \\
\text { blotches }\end{array}$ & $\begin{array}{l}\text { Mixed red- } \\
\text { wild type }\end{array}$ & Wild-type & \\
\hline$F_{1}$ & $\begin{array}{l}F_{1} \\
F_{2}\end{array}$ & $\begin{array}{l}1 \\
2 \\
3\end{array}$ & $\begin{array}{l}298 \\
355 \\
300\end{array}$ & $\begin{array}{l}\mathrm{Rr} \\
\mathrm{Rr} \\
\mathrm{Rr}\end{array}$ & $\begin{array}{l}\mathrm{Rr} \\
\mathrm{Rr} \\
\mathrm{Rr} \\
\text { Total }\end{array}$ & $\begin{array}{l}135 \\
144 \\
139 \\
691\end{array}$ & $\begin{array}{l}90 \\
95 \\
88 \\
261\end{array}$ & $\begin{array}{l}10 \\
26 \\
12 \\
3: 1\end{array}$ & $\begin{array}{l}63 \\
90 \\
60\end{array}$ & $\begin{array}{l}3: 1 \\
3: 1 \\
3: 1\end{array}$ \\
\hline Red & $\begin{array}{l}\mathrm{F} 1 \\
\mathrm{BcF}_{1}\end{array}$ & $\begin{array}{l}1 \\
2 \\
3\end{array}$ & $\begin{array}{l}280 \\
345 \\
311\end{array}$ & $\begin{array}{l}\mathrm{Rr} \\
\mathrm{Rr} \\
\mathrm{Rr}\end{array}$ & $\begin{array}{l}\mathrm{Rr} \\
\mathrm{Rr} \\
\mathrm{Rr} \\
\text { Total }\end{array}$ & $\begin{array}{l}120 \\
159 \\
134 \\
702\end{array}$ & $\begin{array}{l}90 \\
100 \\
99 \\
234\end{array}$ & $\begin{array}{l}15 \\
20 \\
19 \\
3: 1\end{array}$ & $\begin{array}{l}55 \\
66 \\
59\end{array}$ & $\begin{array}{l}3: 1 \\
3: 1 \\
3: 1\end{array}$ \\
\hline GIFT & $\begin{array}{l}\mathrm{F} 1 \\
\mathrm{nBcF}_{1}\end{array}$ & $\begin{array}{l}1 \\
2 \\
3\end{array}$ & $\begin{array}{l}305 \\
326 \\
335\end{array}$ & $\begin{array}{l}\mathrm{rr} \\
\mathrm{rr} \\
\mathrm{rr}\end{array}$ & $\begin{array}{l}\mathrm{Rr} \\
\mathrm{Rr} \\
\mathrm{Rr} \\
\text { Total }\end{array}$ & $\begin{array}{l}107 \\
113 \\
117\end{array}$ & $\begin{array}{l}45 \\
50 \\
57 \\
489\end{array}$ & $\begin{array}{l}30 \\
43 \\
47\end{array}$ & $\begin{array}{l}123 \\
120 \\
127 \\
490\end{array}$ & $\begin{array}{l}1: 1 \\
1: 1 \\
1: 1 \\
1: 1\end{array}$ \\
\hline
\end{tabular}

Rep= Number of replicates, $\mathrm{N}=$ Offspring number

The intermediate (mixed red-wild type) colour phenotype found in this study over two generations suggested that a simple dominant-recessive inheritance system may not be applied. The deviation indicated that the colour inheritance may be controlled by other non-Mendelian system since the dominant red allele (RR or $\mathrm{Rr}$ ) produced an intermediate phenotype (mixed red-wild type) in a heterozygous form (Rr). According to the hatchery record, the Red hybrid tilapia stock reared in UPM hatchery was produced through hybridization between 0 . mossambicus with 0 . niloticus, however, the exact strain (whether a Thai strain, Philippine red strain or Taiwanese strain) could not be verified based on the record alone.

The fact that $\mathrm{F}_{2}$ and backcrosses $\left(\mathrm{BCF}_{1}\right.$ and $\left.\mathrm{nBCF}_{1}\right)$ all produced mixed red-wild type colour phenotype suggested an incomplete dominant pattern of inheritance for the current GIFTred hybrid crosses. Huang et al. (1998) inferred the red body color of 0 . mossambicus $\times 0$. niloticus and even in Taiwanese Red hybrid tilapia was inherited as a single gene with incomplete dominance. Nevertheless, Lovshin et al. (1990) opined that colour determination in tilapia is complicated because of the diverse genetic make-up of Red hybrid tilapia hybrids and colour variations of red that have been described among off-spring from a common female. Additionally, some colour phenotypes are subviable and some phenotypes change colour over time making genetic determination of colour complex.

The proportion of reddish coloured phenotypes in $F_{1}$ hybrid, however, differed between reciprocal crosses depending on the male parental species used for the experiment. A high percentage (average $46.28 \%$ ) of red coloured type hybrid were observed when male Red hybrid tilapia was selected as broodstock, but low percentage (average 29.80\%) of red type coloured hybrid were found when male GIFT tilapia (wild type colour) was used as broodstock. Likewise, a high percentage of hybrid fish exhibiting wild type colour phenotype was observed when GIFT Tilapia was assigned as a male parent (42.25\%) when compared with the Red hybrid tilapia male $(20.49 \%)$ in the study.

Therefore, the results of this study suggested that the gene responsible for colour determination in tilapia might be located or linked with the male Y-chromosome, where a red hybrid tilapia male presumably would produce higher percentage of reddish coloured offsprings as compared to wild type male parent. A related study by Parnell and Steelman (2013) using quantitative trait loci analysis of restriction site-associated DNA -tag single nucleotide polymorphisms (SNPs) indicated the chromosomal linkage between the orange blotch colour and ZW chromosome in tilapia, which further supported the assumption.

In conclusion, the crossbreeding experiment between Red hybrid tilapia and GIFT tilapia was carried out successfully under laboratory conditions, and the colour inheritances of $F_{1} F_{2}$ and backcrosses hybrids were examined. The outcomes of this study showed that crossbreeding between the two tilapia species produced an intermediate phenotype (mixed red-wild-type) which indicate incomplete dominant inheritance pattern. Overall, the results of this study would be useful and important for conducting and managing proper breeding scheme and propagation of $F_{1}$ hybrid and/or later generation hybrids either in a laboratory, intensive or even extensive hatchery scales. 


\section{Acknowledgments}

The authors would like to thank all the staff of the Department of Aquaculture, Faculty of Agriculture, UPM and lab mates from Fish Genetics and Breeding laboratory, who have assisted in this project. The authors would also like to take this opportunity to thank Universiti Putra Malaysia for the opportunity to conduct the research. The study was part of the PhD thesis of O.F. Nwachi.

\section{References}

Beardmore, J.A., G.C. Mair and R.I. Lewis: Monosex male production in finfish as exemplified by tilapia: Applications, problems, and prospects Aquaculture, 197, 283-301 (2001).

Benhaïm, D., D.D. Akian, M. Ramos, S. Ferrari, K. Yao and M.L. Bégout: Self-feeding behaviour and personality traits in tilapia: A comparative study between Oreochromis niloticus and Sarotherodon melanotheron. Appl. Anim. Behav. Sci., 187, 85-92 (2017).

Bentsen, H.B., B. Gjerde, A.E. Eknath, M.S.P. de Vera, R.R. Velasco, J.C. Danting, E.E. Dionisio, F.M. Longalong, R.A. Reyes, T.A. Abella, M.M. Tayamen and R.W. Ponzoni: Genetic improvement of farmed tilapias: Response to five generations of selection for increased body weight at harvest in Oreochromis niloticus and the further impact of the project'. Aquaculture, 468, 206-217 (2017).

Ferreira, J.: On the inheritance of the red colour in the Mozambique Tilapia Oreochromis mossambicus. MADOQUA, 1, 5-8 (1989).

Hamzah, A., R.W. Ponzoni, N.H. Nguyen, H.L. Khaw, H.Y. Yee and S. Mohd Nor: Performance of the genetically improved farmed tilapia (GIFT) strain over ten generations of selection in Malaysia. Pert. J. Trop. Agri. Sci., 37, 411-429 (2014).

Huang, C.M., S.L. Chang, H.J. Cheng and I.C. Liao: Single gene inheritance of red body coloration in Taiwanese Red hybrid tilapia. Aquaculture, 74. 227-232 (1988).

Lago, A. de A., T.T. Rezende, M.A.D. Dias, R.T.F. Freitas and A.W.S Hilsdorf: The development of genetically improved Red hybrid tilapia lines through the backcross breeding of two Oreochromis niloticus strains. Aquaculture, 472, 17-22 (2017).

Lovshin, L.L., D. Tave and A.O. Lieutaud: Growth and yield of mixed-sex, young-of-the-year Oreochromis niloticus raised at two densities in earthen ponds in Alabama, U.S.A. Aquaculture, 89, $21-26$ (1990).

McAndrew, B.J., F.R. Roubal, R.J. Roberts, A.M. Bullock and I.M. McEwen. The genetics and histology of red, blond and associated colour variants in Oreochromis niloticus. Genetica, 76, 127-137 (1988).

Neira, R., X. García, J.P. Lhorente, M. Filp, J.M. Yáñez and A.M. Cascante: Evaluation of the growth and carcass quality of diallel crosses of four strains of Nile tilapia (Orochromis niloticus), Aquaculture, 451, 213-222 (2015).

$\mathrm{Ng}$, W.K. and R. Hanim: Performance of genetically improved Nile tilapia compared with red hybrid tilapia fed diets containing two protein levels. Aquaculture Res., 38, 965-972 (2007).

Nwachi, O.F and Y.B. Esa: Comperative Growth and survival of diploid and triploid Mozambique Tilapia (Oreochromis mossambicus) reared in indoor tanks. J. Environ. Biol, 37, 839-843 (2016).

Parnell, N. and J.T. Streelman: Genetic interactions controlling sex and color establish the potential for sexual conflict in Lake Malawi cichlids. Heredity, 110, 239-246 (2013).

Pongthana, N., N.H. Nguyen and R.W. Ponzoni: Comparative performance of four Red hybrid tilapia strains and their crosses in fresh- and saline water environments. Aquaculture, 308, 109-114 (2010).

Rajaee, A.H., F.A. Huntingford, K.J. Ranson, B.J. McAndrew and D.J. Penman: The effect of male colouration on reproductive success in Nile tilapia (Oreochromis niloticus). Aquaculture, 308, 119-123 (2010).

Reich, L., J. Don and R.R. Avtalion: Inheritance of the red color in tilapias. Genetica, 1, 195-200 (1990).

Thodesen, J., D. Ma, M. Rye, Y. Wang, S. Li, H.B. Bentsen, M.H. Yazdi and T. Gjedrem: Genetic improvement of tilapias in Chinal : Genetic parameters and selection responses in growth , survival and external color traits of Red hybrid tilapia (Oreochromis spp .) after four generations of multi-trait selection, Aquaculture, 417, 354-366 (2013).

Thodesen, J., M. Rye, Y.X. Wang, S.J. Li, H.B. Bentsen, M.H. Yazdi and T. Gjedrem: Genetic improvement of tilapias in China: Genetic parameters and selection responses in growth, survival and external color traits of Red hybrid tilapia (Oreochromis spp.) after four generations of multi-trait selection. Aquaculture, 416, 354-366 (2013).

Trevas, E.: The biology and cultur of tilapias ICLARM Conference proceedings. In: (Eds.: R.V.C. Pullen and R.H. Lowe- McConnell). Tilapias; taxonomy and speciation. No 7 ICLARM Manila Phillipines, pp. 3-13 (1982).

Watanabe, W.O., T.M. Losordo, K. Fitzsimmons and F. Hanley: Tilapia Production Systems in the Americas: Technological Advances, Trends, and Challenges. Rev. Fish. Sci., 10, 465-498 (2002).

Wohlfarth, G.W., S. Rothbard, G. Hulata and D. Szweigman: Inheritance of red body coloration in Taiwanese tilapias and in Oreochromis mossambicus. Aquaculture, 84, 219-234 (1990). 